\title{
Effects of amphetamine, Dexamyl and meprobamate on poor shuttle-box avoidance performers
}

DENNIS K. KAMANO, BARBARA J. POWELL AND LOUIS K. MARTIN GALESBURG STATE RESEARCH HOSPITAL

Amphetamine, Dexamyl and meprobamate were utilized in an effort to improve avoidance behavior in rats poor in avoidance performance. It was found that CAR acquisition among poor shuttle-box avoidance performers improved significantly with Dexamyl, but not with amphetamine and meprobamate.

In shuttle-box avoidance studies one consistently finds that a certain number of animals fail to meet the learning criterion regardless of the extent of training (e.g., Brush, 1966; Kamano, Powell, Martin, \& Ogle, in press). Efforts to improve avoidance learning among such Ss with drugs have shown some promise. For example, Rech (1966) reported that amphetamine improved avoidance acquisition in poor performing rats.

The purpose of this study was to determine what effects known enhancers of CAR acquisition, such as amphetamine (Krieckhaus, 1965; Krieckhaus, Miller, \& Zimmerman, 1965), Dexamyl (Powell, Martin, \& Kamano, in preparation), and meprobamate (Powell, Martin, \& Kamano, 1965b) would have on poor shuttlebox avoidance performers.

\section{Subjects}

Twenty albino Wistar rats which falled to acquire a CAR were obtained from a series of shuttle-box avoidance conditioning studies conducted at our laboratory. The studies from which the Ss were secured utilized 120 conditioning trials and learning failure was defined as $15 \%$ or less CAR acquisitions over the total trials and the last 30 trials.

\section{Procedure}

Approximately $24 \mathrm{hr}$. after learning failure had been established, the Ss were assigned on a predetermined random order to four groups, and were given IP injections of $2 \mathrm{mg} / \mathrm{kg}$ d-amphetamine sulfate in normal saline, Dexamyl (1.18 $\mathrm{mg} / \mathrm{kg}$ d-amphetamine sulfate and $15 \mathrm{mg} / \mathrm{kg}$ amobarbital sodium combination) in normal saline, $80 \mathrm{mg} / \mathrm{kg}$ meprobamate dissolved in a $25 \%$ solution of polyethylene glycol 300 , or normal saline (placebo) equivalent to $2 \mathrm{cc} / \mathrm{kg}$, respectively, $20 \mathrm{~min}$. prior to each conditioning session. The Ss were given 10 conditioning trials per day for five days, a total of 50 trials. The apparatus and conditioning procedure were identical to that employed in the studies from which the Ss were obtained. The apparatus was a modified Mowrer-Miller shuttle box with a 4-in. hurdle dividing the two compartments and a 60-W light bulb as the CS. Shock, as the US, was delivered through the grid floor at 250 microvolts. Details of the apparatus and shock source are described elsewhere (Kamano, Martin, \& Powell, 1966). Each conditioning session was preceded by a 1-min. interval after which the CS was flashed for $5 \mathrm{sec}$. followed by the US. Both CS and US remained on until S crossed the hurdle into the opposite compartment. This procedure was repeated at intervals varying from 20 to $40 \mathrm{sec}$. in a predetermined random order with an average of $30 \mathrm{sec}$. Crossing the hurdle during the 5-sec. CS-US interval was scored as an avoidance response.

\section{Results and Discussion}

The means and standard deviations of avoidance responses and intertrial hurdle-crossings (IH-C) over the total acquisition period for the four groups are presented in Table 1.

A Kruskal-Wallis one-way analysis of variance of the CAR scores for the different groups revealed significant effects of drug $(H=12.02, p<.01)$. Application of individual Mann-Whitney $U$ tests indicated that Dexamyl differed significantly from amphetamine $(p=$ $.029)$, as well as from meprobamate $(p=.014)$, and placebo $(p=.004)$; amphetamine differed significantly from meprobamate $(p=.014)$. These results indicated that improved CAR acquisition was a function of Dexamyl. Although the effect of amphetamine was in the expected direction, it was not significantly different from placebo $(p=.141)$.

Similar analyses of the number of $\mathrm{IH}-\mathrm{C}$ also revealed significant effects of drug ( $H=12.78, p<.01)$. However, in this case the Dexamyl and amphetamine groups did not differ significantly from each other, but both differed significantly from the groups treated with meprobamate $(p=.014)$ or placebo $(p=.008)$.

The fact that Dexamyl increased avoidance behavior and $\mathrm{IH}-\mathrm{C}$ is consistent with a recent study of Powell et al. 1 Although this could mean that Dex-

Table 1

Means and SDs of Avoidance Responses and Intertrial Hurdle-Crossings

\begin{tabular}{|c|c|c|c|c|c|}
\hline Group & $\mathbf{N}$ & $\begin{array}{c}\text { Avoidance } \\
\text { Mean }\end{array}$ & $\begin{array}{c}\text { Response } \\
\text { SD }\end{array}$ & $\begin{array}{l}\text { Hurdle- } \\
\text { Mean }\end{array}$ & $\begin{array}{l}\text { Crossing } \\
\text { SD }\end{array}$ \\
\hline Amphetamine & 4 & 17.00 & 5.87 & 24.25 & 24.31 \\
\hline Dexamyl & 4 & 35.75 & 9.85 & 19.75 & 14.24 \\
\hline Meprobamate & 4 & 5.50 & 4.36 & 2.75 & 2.06 \\
\hline Placebo & 8 & 10.13 & 9.40 & 3.38 & 4.27 \\
\hline
\end{tabular}


amyl facilitated avoidance behavior by increasing IH-C and thereby the probability of an active avoidance response, the results with amphetamine cast serious doubt on such an interpretation. Amphetamine increased IH-C but did not improve CAR acquisition, a finding consistent with another study (Powell, Martin, \& Kamano, 1965a). Increasing activity level per se does not invariably improve CAR acquisition. While it might be correct to term CARs emitted by amphetamine Ss as correlates of increased activity level, this does not hold true for Dexamyl. Dexamyl appears to have the dual effect of improving shuttle-box avoidance behavior and increasing activity level.

\section{References}

Brush, F. R. On the differences between animals that learn and do not learn to avoid electric shock. Psychon. Sci., 1966, 5, 123-124.

Kamano, D. K., Martin, L. K., \& Powell, B. J. Avoidance response acquisition and amobarbital dosage levels. Psychopharmacologia, $1966,8,319-323$.
Kamano, D. K., Powell, B. J., Martin, L. K., \& Ogle, M. E. Amobarbital effects on extinction and spontaneous recovery of active avoidance. Psychol. Rec., in press.

Krieckhaus, E. E. Decrements in avoidance behavior following mammillothalamic tractotomy in rats and subsequent recovery with d-amphetamine. J. comp. physiol. Psychol., 1965, 60, 31-35.

Krieckhaus, E. E., Miller, N. E., \& Zimmerman, P. Reduction of freezing behavior and improvement of shock avoidance by d-amphetamine. J. comp. physiol. Psychol., 1965, 60, 36-40.

Powell, B. J., Martin, L. K., \& Kamano, D. K. Failure to find improved shuttle-box avoidance performance using d-amphetamine sulfate. Psychol. Rep., 1965a, 17, 330.

Powell, B. J., Martin, L. K., \& Kamano, D. K. Effects of amobarbital sodium and meprobamate on acquisition of conditioned avoidance. Psychol. Rep., 1965b, 17, 691-694.

Rech, R. H. Amphetamine effects on noor performance of rats in a shuttle-box. Psychopharmacologia, 1966, 9, 110-117.

\section{Note}

1. B. J. Powell, L. K. Martin, \& D. K. Kamano, “Significant factors in avoidance performance of rats receiving d-amphetamine and amobarbital combinations," in preparation. 